\title{
O EROTISMO COMO ELEMENTO CAPAZ DE PROMOVER O DIÁLOGO ENTRE CULTURAS E GRUPOS ÉTNICOS DIFERENTES \\ EL EROTISMO COMO ELEMENTO CAPAZ DE PROMOVER EL DIÁLOGO ENTRE CULTURAS Y GRUPOS ÉTNICOS DIFERENTES
}

\section{EROTICISM THE DIALOGUE BETWEEN DIFFERENT CULTURES AND ETHNIC GROUPS}

\section{L'ÉROTISME LE DIALOGUE ENTRE DIFFÉRENTES CULTURES ET GROUPES ETHNIQUES}

DOI: $10.5533 / 1984-2503-20135107$

\section{Márcia Cavendish Wanderley ${ }^{1}$}

\section{RESUMO}

É possível levantar a hipótese de erotismo - mais presente em alguns tipos humanos do que em outros - como um elemento capaz de reunir os povos de diferentes culturas e etnias e promover o diálogo entre eles. Mais do que uma simples hipótese, esta é uma afirmação central, feita por Gilberto Freyre em seu notável livro Casa Grande \& Senzala, no que diz respeito à atitude dos portugueses colonizadores em relação às terras conquistadas, tendo em mente principalmente o Brasil. Pela primeira vez traduzido para o inglês com o título The Masters and the Slaves, o livro recebeu muitas críticas a partir de 1930 em diante por seus voos intelectuais, por ter criado uma visão quase realista da sociedade colonial brasileira e, desta forma escondendo os conflitos inerentes à escravidão. Ele também ajudou a desenvolver um conceito de democracia racial supostamente predominante hoje no Brasil. Não obstante, o livro tem readquirido estima entre os leitores e não só por causa de sua força literária excepcional. A originalidade de seus argumentos contraditórios também veio à tona, como uma espécie de crítica em ziguezague. A partir de outro ponto de vista, a patologia de uma sociedade patriarcal emerge da Casa Grande \& Senzala e os leitores são capazes de ver que as relações

\footnotetext{
${ }^{1}$ Mestre em Sociologia e Doutora em Literatura Brasileira, fez estudos de Pós-doutorado nas Universidades de Montreal no Canadá e Yale, nos EEUU além da USP, Brasil. É Professora da Pós-Graduação em Sociologia e Direito da UFF. E-mail: marciacw@centroin.com.br
} 
sexuais naquela sociedade eram governadas por dominação e exploração. Se levarmos em conta o que Foucault diz em A História da Sexualidade (Vol. II), veremos o princípio do isomorfismo na relação sexual.

Palavras-chave: Estudos culturais, história brasileira, Sociologia, grupos étnicos, erotismo.

\section{RESUMEN}

Es posible formular la hipótesis de erotismo - más presente en algunos tipos humanos que en otros - como un elemento capaz de reunir los pueblos de diferentes culturas y etnias y promover el diálogo entre ellos. Más que una hipótesis, esta es una afirmación central hecha por Gilberto Freyre en su notable libro Casa Grande \& Senzala, en lo que respecta a la actitud de los portugueses colonizadores en relación a las tierras conquistadas, sobre todo el Brasil. Traducido al inglés por la primera vez con el título The Masters and the Slaves, el libro recibió muchas críticas a partir de 1930 por sus vuelos intelectuales, por haber creado una visión casi realista de la sociedad colonial brasileña y, de esta manera, escondiendo los conflictos inherentes a la esclavitud. Además, él ha ayudado a desarrolar un concepto de democracia racial supuestamente hoy predominante en Brasil. No obstante, el libro ha readiquirido estima entre los lectores y no solamente en razón de su fuerza literaria excepcional. La originalidad de sus argumentos contradictorios también ha aparecido como una especie de crítica en zigzag. A partir de otro punto de vista, la patología de una sociedad patriarcal emerge de Casa Grande \& Senzala y los lectores son capazes de ver que las relaciones sexuales en aquella sociedad eran gobernadas por dominación y exploración. Si consideramos lo que dice Foucault en $L a$ Historia de la Homosexualidad (Vol. III), veremos el principio del isomorfismo en la relación sexual.

Palabras clave: Estudios culturales, historia brasileña, Sociología, grupos étnicos, erotismo.

\section{ABSTRACT}

Eroticism - more present in some human types than others - may be defended as able to bring together people from different cultures and ethnicities and promote dialogue between them. More than just a simple hypothesis, this is a affirmation central to Gilberto Freyre's remarkable book Casa Grande \& Senzala regarding the attitude displayed by Portuguese colonisers towards the conquered lands, and in particular, Brazil. Translated for the first time to English as The Masters and the Slaves, the book became the subject of 
widespread criticism in 1930 for its intellectual flights and creating an almost realistic vision of Brazilian colonial society and therefore masking the conflicts inherent to slavery. It also served to develop a concept of racial democracy which is supposedly predominant in modern Brazil. The book has however come back into favour among readers, and not just due to its exceptional literary force. The originality of its contradictory arguments has also come to light as a type of zigzag criticism. From another point of view, the pathology of a patriarchal society emerges from Casa Grande \& Senzala to reveal to its readers how the sexual relations in such a society were governed by domination and exploitation. Considering what Foucault says in The History of Sexuality (Vol. II) allows us to see the principle of isomorphism in sexual relations.

Key words: cultural studies, Brazilian history, sociology, ethnic groups, eroticism.

\section{RÉSUMÉ}

II est possible d'émettre l'hypothèse de ce que l'érotisme - plus présent chez certains groupes humains que chez d'autres - peut représenter un élément capable de réunir des peuples de différentes cultures et ethnies, ainsi que de promouvoir le dialogue entre ceuxci. Plus qu'une simple hypothèse, cette affirmation constitue un point central de la réflexion de Gilberto Freyre dans son célèbre ouvrage Casa Grande \& Senzala [Maîtres et esclaves], plus particulièrement en ce qui concerne l'attitude des colons portugais par rapport aux terres conquises, et dans le cas qui nous intéresse, au Brésil. Traduit en anglais sous le titre The Masters and the Slaves, le livre a souffert de nombreuses critiques à partir de 1930 en raison de ses envolées intellectuelles et de la création d'une vision de la société coloniale brésilienne qui aurait tendance à cacher les conflits inhérents à l'esclavage. L'ouvrage a également contribué à développer le concept d'une démocratie raciale soi-disant prédominante dans le Brésil contemporain. II a néanmoins retrouvé un certain prestige parmi les lecteurs, et pas seulement en raison de son exceptionnelle force littéraire. L'originalité de ses arguments contradictoires a également su s'imposer comme une sorte de critique en zigzag. À partir d'un autre point de vue, la pathologie d'une société patriarcale émerge de Casa Grande \& Senzala et les lecteurs sont en mesure d'y voir que les relations sexuelles de cette société étaient gouvernées par la domination et l'exploitation. Si l'on prend en compte ce que dit Foucault dans son Histoire de la sexualité (Vol. II), l'on peut constater la présence du principe d'isomorphisme au sein du rapport sexuel.

Mots-clés: études culturelles, histoire brésilienne, sociologie, groupes ethniques, érotisme. 


\section{Introdução}

É possível sustentar e comprovar a hipótese de que o erotismo é um elemento capaz de reunir pessoas de grupos étnicos diferentes e até conflitantes promovendo um diálogo entre elas? Mais do que uma hipótese, esta foi uma afirmação feita por Gilberto Freyre nas primeiras décadas do século XX, em seu marcante livro Casa Grande \& Senzala, tomando como base o comportamento do português colonizador em suas relações com os povos por ele conquistados, em especial, os africanos trazidos ao Brasil como escravos e utilizados inicialmente, como mão-de-obra na implantação do cultivo da cana em terras do Nordeste da Colônia, e mais tarde trasladados a outras regiões onde a economia floresceu (Triângulo Mineiro e Vale do Paraíba do Sul) na garimpagem do ouro e pedras preciosas, e no cultivo café. Usando uma expressão mais cuidadosa para destacar o fenômeno que apontava, Gilberto Freyre afirmou que:

Vencedores no sentido militar e técnico sobre as populações indígenas, dominadores absolutos dos negros importados da África para a dura faina do engenho, os europeus tiveram, sem dúvida, que conviver com índios e africanos no que diz respeito a relações genéticas e sociais. A escassez de mulheres brancas criou zonas de confraternização entre vencedores e vencidos, entre amos e escravos. As relações dos brancos com as mulheres de cor, sem deixar de serem de superiores para inferiores e na maioria dos casos de senhores despóticos e sádicos com passivas escravas, foram mitigadas com a necessidade experimentada pelos colonos de constituir família, dentro destas circunstâncias e sobre esta base 2 .

Sem dúvida são afirmações procedentes e a miscigenação resultante dessa "confraternização" é um testemunho eficaz da aproximação ocorrida entre as raças. Entretanto a natureza dessas aproximações foi, na maior parte das vezes, conflituosa e não harmônica como seria de esperar-se a partir das afirmações acima sustentadas e os resultados raramente podem chamar-se de "confraternização. Gilberto Freyre sabia disso muito bem e Casa Grande \& Senzala não é texto que negue essa evidência, pois faz, pelo contrário, a denúncia dos horrores da escravidão, mas esta é suavizada pelo próprio romantismo do autor, na descrição das relações interpessoais entre escravas e escravos negros e seus senhores.

\footnotetext{
${ }^{2}$ Freyre, Gilberto (1977). Casa Grande y senzala. Introdución a la Historia de la Sociedad Patriarcal en el Brasil, Venezuela: Biblioteca Ayacucho.
} 
Gilberto Freyre foi inovador na antropologia brasileira e adquiriu posições teóricas e ideológicas em seu contato acadêmico com intelectuais do naipe de Franz Boas e $\mathrm{H}$. Giddens de quem foi aluno na Universidade de Colúmbia nos Estados Unidos. Estas levaram-no a afirmar a necessidade de separar os critérios de cultura e raça na análise histórica dos povos e a eleger a cultura como o caminho mais lúcido na realização desta tarefa:

Foi o estudo da antropologia sob a orientação do Prof. Boas o que primeiro me revelou o negro e o mulato em seu justo valor, separados os traços de raça, dos efeitos ambientais ou da experiência cultural. Neste critério de diferenciação fundamental entre raça e cultura, se apóia todo o plano deste ensaio ${ }^{3}$.

Também não está afastada totalmente da visão do autor, algo do critério materialista de análise de sociedades:

Temos de admitir a influência considerável, ainda que nem sempre preponderante da técnica da produção econômica sobre a estrutura das sociedades na caracterização de sua fisionomia moral [...] poderosa como nenhuma na capacidade de aristocratizar ou de democratizar as sociedades [... $]^{4}$.

Eram idéias bem progressistas para o Brasil dos anos 30 quando imperavam aqui as teses racistas não apenas de origem europeia (Conde de Gobineau), pois também nos Estado Unidos predominavam as políticas anti-imigratórias contra as correntes, principalmente, quando oriundas de países europeus meridionais e latino americanos, considerados como de uma raça inferior à nórdica pelos americanos do Norte. Enfim, não podemos deixar de admitir que essas idéias de Freyre naquele Brasil racista, eram revolucionárias e como tal foram comemoradas pela recepção calorosa que o acolheu não apenas nacional como internacionalmente e até hoje reverbera em plano mundial. Aqui dentro, sobretudo a partir dos anos 50, esse panorama receptivo se transforma em repúdio e mesmo em intelectuais que o admiram assim como às suas descobertas, podese sentir a ponta de ironia perpassando os elogios, como é o caso de Darcy Ribeiro em seu prólogo à edição venezuelana do livro de que falamos.

Ao largo de toda a respeitosa extensão de Casa Grande \& Senzala, o leitor vê exibir-se bem urdido, o vicioso costume de /Gilberto Freyre. Trata-se de uma espécie de bloqueio sentimental, talvez alguma fixação que possui da imagem da ama-escrava, gorda, lustrosa e boa, que não tem olhos para ver o negro da plantação de cana, queimado como um carvão humano, primeiro nos fornos do engenho e nos sembrados de cana, depois nas minas e nos cafezais 5 .

\footnotetext{
${ }^{3}$ Freyre, Gilberto (1977). Casa Grande y senzala, Introdución a la Historia de la Sociedad Patriarcal en el Brasil, Venezuela: Biblioteca Ayacucho, p.7.

${ }^{4}$ Freyre, Gilberto (1977). Casa Grande y senzala, Introdución a la Historia de la Sociedad Patriarcal en el Brasil, Venezuela: Biblioteca Ayacucho, p.7.

${ }^{5}$ Apresentação de Darcy Ribeiro. In Freyre, Gilberto (1977). Op. Cit,, p. XXXVI.
} 
"Que teria acontecido a Freyre, a ponto de sua recepção ter sofrido tamanha reviravolta?"6 indaga-se Luis Costa Lima com muita propriedade. Parece-me que razões não faltaram, e entre elas a mais impeditiva a seu reconhecimento como um intelectual progressista e com descobertas relevantes em termos de interpretação do Brasil, foi sua guinada para a direita a partir dos anos 60 , seus compromissos assumidos com o governo fascista aqui instalado e até sua fama de denunciador disseminado em toda a intelectualidade de esquerda no Brasil. Essa intelectualidade que não hesita, a partir de então, em apontar as falhas e imprecisões de suas análises consideradas como feitas através de um olhar que vê a Senzala a partir das varandas da Casa Grande. Mais que isso, apontava-se o seu narcisismo e o seu anglicismo esnobe, como traços da nobreza patriarcal pernambucana (sic) à qual pertenceria.

Apesar de tudo isto, é impossível resistir ao fascínio de um livro como Casa Grande \& Senzala, misto de obra antropológica, histórica e ao mesmo tempo um grande romance da cultura brasileira em suas origens, como é considerado por muitos. Ricardo Benzanquen de Araújo, um dos intelectuais contemporâneos que fazem a releitura de sua obra com um olhar isento dos preconceitos dos anos 50 e 60, apesar das restrições de caráter não ideológico que Ihe faz, Benzanquen se debruçará sobre os dois livros por ele considerados como os mais fecundos da obra deste sociólogo analisando-os, inclusive em suas propostas modernistas e considerando-as como alternativas ao modernismo paulista. E vendo-as não apenas como conservadoras, mas como um "outro modernismo distinto daquela postura a um só tempo nacionalista e modernizadora que se tornava gradualmente hegemônica entre nós" 7 . Ricardo irá apontar também a visão gilbertiana de sociedade brasileira com ênfase sobre o sincretismo resultante na participação ativa dos diversos segmentos desta sociedade (brancos, negros e índios) contribuindo para sua nova feição, diferente da européia. $E$ de sua sobrevivência garantida por uma espécie de equilíbrio harmônico entre lados opostos e até antagônicos. Equilíbrio que permitiria a existência de zonas de confraternização convivendo com o despotismo que caracterizou as relações entre dominadores e dominados.

Benzanquen não oculta a imprecisão de tal postura teórica, uma condição que Maria Lucia Garcia Pallares Burke explicou com muita propriedade. Ela menciona que o discípulo de Giddens e de Boas em sua formação sócio antropológica, feita nos Estados

\footnotetext{
${ }^{6}$ Costa Lima, L. "Apresentação". In Araujo, Ricardo Benzanquem (1994). Guerra e Paz: Casa Grande \& Senzala e a Obra de Gilberto Freyre nos anos 30, Rio de Janeiro: Editora 34 Letras.

7 Araujo, Ricardo Benzanquem (1994). Guerra e Paz: Casa Grande \& Senzala e a Obra de Gilberto Freyre nos anos 30, Rio de Janeiro: Editora 34 Letras.
} 
Unidos nos anos entre 20 e 30, Gilberto Freyre manteve grande admiração a ambos os mestres aos quais atribui, confessadamente, as raízes de suas ideias a respeito da estrutura da sociedade brasileira ${ }^{8}$. Estas ideias que em Boas priorizam o conceito de cultura na análise de qualquer sociedade e que segundo Freyre, ele próprio assumiu totalmente, já é uma questão problematizada, pois segundo Luis Costa Lima, Freyre "estabeleceria um trânsito direto da cultura com uma concepção étnica, mais precisamente, étnico-climática dos povos" 9 que não seria a esperada em um culturalista No caso de Giddens e Spencer (o evolucionista), ele teria uma outra linha a seguir: a da ideia de que a civilização tem "origem na luta entre duas energias, o Novo e o Velho"; "(a) civilização existe porque nenhum dos dois lados antagônicos vence totalmente e o equilíbrio entre ambos"10, garante, por assim dizer, a sobrevivência dos opostos. Assim, nos explica Maria Lucia Burke,

Não sendo um pensador sistemático e não se incomodando com as imprecisões, Freyre não se detém a explicitar os conceitos ou noções com que trabalha; no entanto, passagens como essas relativizam, no meu entender, o papel de elaborador e difusor de um poderoso sistema ideológico pelo qual foi freqüentemente criticado ${ }^{11}$.

E realmente é esta a grande crítica que lhe fizeram tantos estudiosos da geração 50, a de ter ignorado as contradições da sociedade brasileira que se configuraram a partir de suas raízes históricas e até hoje vigoram. E permitir na contemporaneidade a construção do mito da existência de uma democracia morena ou mulata.

Com estas heranças teóricas (Giddens, Spencer, e porque não Durkheim e Carlile - este último defensor do equilíbrio dos antagonismos) ele não poderia encontrar bom trânsito entre a geração 50 de interpretadores do Brasil quando imperavam academicamente nas ciências humanas e em outras instâncias políticas, as ideias marxistas de análise. Assim, toda a sua inicial revolucionária atitude contra a visão teórica que pregava o branqueamento das raças no Brasil, e principalmente dominava a política dos Estados Unidos da América, em seu afã de controle imigratório, é perdida a partir do momento em que a crítica vê na sua postura política conservadora, como o eco das suas ideias teóricas sobre a miscigenação no Brasil. Uma visão irreal de um paraíso tropical onde várias "raças" convivem sob a batuta do branco colonizador foi a imagem

\footnotetext{
${ }^{8}$ Burke, M. L. G. P (2005). Gilberto Freyre: Um Vitoriano nos Trópicos, São Paulo: Ed. UNESP.

9 Costa Lima, L. (1994). "Apresentação". In Araujo, Ricardo Benzanquem (1994). Guerra e Paz: Casa Grande \& Senzala e a Obra de Gilberto Freyre nos anos 30, Rio de Janeiro: Editora 34 Letras.

10 Burke, M. L. G. P. (2005). Op. Cit, p. 374.

${ }^{11}$ Burke, M. L. G. P. (2005). Op. Cit, p. 374.
} 
desenhada por muitos a respeito de Casa Grande \& Senzala, que assim perde muito de seu status antropológico e político talvez devido a seus controvertidos argumentos que resultam num zig zag crítico como disse Ricardo Bezanquen de Araújo ${ }^{12}$.

Por outro lado, na patologia que emerge de Casa Grande \& Senzala, pode-se perceber que as relações sexuais que acontecem dentro dessa sociedade regulada pelo arbítrio, seguem o mesmo modelo de dominação e exploração observado nas interações entre os grupos econômicos, políticos e sociais. Isto é, são relações de dominação despótica e violenta entre vencedores e vencidos que se repetem nas relações sexuais entre os mesmos grupos e contaminam toda a sociedade arquitetada sobre o estigma da violência: de brancos contra negros, de pais contra mulheres e filhos quer sejam estes considerados legítimos ou ilegítimos. Se levarmos em conta as afirmações de Foucault no volume II da História da Sexualidade ${ }^{13}$, veremos que suas ideias a respeito do isomorfismo existente entre as relações sexuais e as relações sociais de uma determinada sociedade, estão baseadas na polaridade existente entre dominadores e dominados entre superiores e inferiores, entre conquistadores e conquistados, tal como o dos papéis dos atores empenhados nestas relações sociais. $E$ se isto não acontece apenas no Brasil, mas em quaisquer sociedades onde condições semelhantes de convivência se apresentem, nos colocamos a seguinte questão. Como é possível falar de erotismo como elemento capaz de promover o diálogo entre culturas diferentes, se as dominações político e econômica permanecerem?

Só é possível responder a essa pergunta a partir da voz do objeto. Nenhum antropólogo estruturalista ou levy-straussiano teve essa preocupação. Gilberto Freyre também não. Desenvolver uma sensibilidade que capte a realidade do objeto e medir o efeito desta escuta nas intersubjetividades. Esta é uma das tônicas da contemporaneidade. Vejamos então a mesma questão a partir do ângulo de um estudioso das matrizes africanas de nossa cultura, integrado ao movimento de resistência cultural negra no Brasil como é o caso de Nei Lopes (premiado com a medalha de Honra ao Mérito Cultural do Governo Federal Brasileiro). Consciente da influência eurocentrista no pensamento brasileiro, ele busca através do estudo dos grupos Bantos e Malês a recuperação da nossa identidade negra, vilipendiada por tantas teses racistas da história e da antropologia de nosso passado recente. Silvio Romero foi um destes historiadores que afirmou: povos negros que entraram em nossa formação eram quase todos do grupo

\footnotetext{
${ }^{12}$ Araujo, Ricardo Benzanquem (1994). Op. Cit.

${ }^{13}$ Foucault, Michel (1984). Historia da sexualidade II: a vontade de saber, Rio de Janeiro: Edições Graal.
} 
bantu "(s)ão gentes ainda no período do fetichismo, brutais, submissas e robustas, as mais próprias para os árduos trabalhos de nossa lavoura rudimentar" ${ }^{14}$. Afrânio Peixoto ${ }^{15}$ e Nina Rodrigues ${ }^{16}$ fizeram coro a estas afirmações que procuravam desvalorizar nossas raízes negras e Oliveira Viana vai mais longe afirmando que "os negros puros, vivendo nas florestas do Congo ou da Angola, nunca criaram civilização alguma"17.

Se os negros brasileiros eram prioritária e estatisticamente originários dos grupos bantos então não valiam muito, era o que dizia o mito da inferioridade intelectual e social negra criado pela própria intelectualidade de então. Mito que reverberava entre a população negra atrapalhando mais ainda a construção de uma identidade já difícil de reconstruir, atormentada sempre pelo fantasma do escravismo passado e perpetuado no estigma que rondava a cor da pele. Todos estes autores, ante os quais, justiça lhe seja feita, Gilberto Freyre iria se contrapor, esqueceram as condições em que os africanos

[...] aqui chegavam, depois de meses de fome e torturas, despersonalizados, desestruturados física e psicologicamente de maneira irreversível. Enredados, então, num juízo apriorístico, esses estudos sobre o negro brasileiro só viram as aparências, não souberam definir com clareza os conceitos de Banto e sudanês; não mostraram os diversos contextos históricos em que esses bantos vieram para o Brasil; não falaram das grandes civilizações florescidas nas partes meridional, central e oriental da áfrica, antes da chegada dos portugueses; não mencionaram a formidável pilhagem e destruição que esses portugueses levaram a efeito em território africano; não se aprofundaram na heróica organização e resistência levada a efeito em território africano; não se aprofundaram na heróica e organizada resistência dos africanos à escravização e ao domínio colonial; não viram a República livre de Palmares como um Estado criado e dirigido por Bantos; confundiram etnias com portos de embarque; não estudaram os Bantos, enfim ${ }^{18}$.

A citação é longa, porém necessária porque a denúncia se estende até mesmo a Gilberto Freyre, apesar de sua preocupação em apontar os maus tratos sofridos por estes africanos e seus descendentes, tratados como animas e ainda que as zonas de confraternização possam ter existido. Na verdade, nenhum destes historiadores e antropólogos preocupou-se em registrar a resistência negra à escravidão que começa a acontecer ainda na África contra os portugueses que invadiram a atual Mauritânia em 1442 com a finalidade de incrementar o comércio escravista que foi se estendendo pela costa africana até atingir a foz do rio Congo. Mas a ocupação da África não foi feita de forma pacífica e as lutas foram sangrentas com perdas estatísticas enormes de todos os que se rebelaram, sejam malês ou bantos, entre outras etnias, mas também do lado

\footnotetext{
${ }^{14}$ Romero, Sílvio (1953). História da literatura brasileira, Rio de Janeiro: J. Olympio.

15 Peixoto, Afrânio (1980). Breviário da Bahia, Rio de Janeiro: MEC - Conselho Federal de Cultura.

${ }^{16}$ Rodrigues, Nina (1977). Os africanos no Brasil, São Paulo: Cia Editora Nacional.

${ }^{17}$ Vianna, Oliveira (1959). Raça e assimilação, Rio de Janeiro: J. Olympio.

${ }^{18}$ Lopes, Nei (2006). Bantos, Malês e Identidade Negra, Belo Horizonte: Autêntica, p.95.
} 
português. E este processo se continua no Brasil através das fugas dos escravos para os chamados Quilombos, verdadeiras cidades Estado; com organização produtiva e autosuficientes em suas necessidades de sobrevivência e de combates.

A quantidade enorme de Quilombos que se distribuiu pelo Brasil durante o período escravocrata é um indício de que o sentimento de identidade negra e a consciência da injustiça vital a que eram submetidos impedia os sentimentos de confraternização em direção aos provocadores de seus males embora sentimentos contraditórios possam cohabitar a alma humana nas relações de intimidade, como foram as provocadas pelo colonizador ao procurarem as escravas para o intercurso sexual e fabricando filhos bastardos, mulatos que foram alimentados e criados dentro da Casa Grande, estabelecendo-se então entre estes as relações de família ou relações fraternas, de que nos fala Gilberto Freyre. Este é um argumento favorável que usamos inicialmente para comprovar uma hipótese que aponta para uma saída possível e simpática para os vários conflitos que se espalham hoje pelo mundo globalizado, conflitos estes provocados pelo confronto entre etnias que não se aceitam mutuamente em suas especificidades. Veja-se o caso de judeus e árabes que se espremem em faixas de terra vizinhas sem jamais se tocarem harmoniosamente. Para não falar de conflitos instalados entre etnias diversas vivendo dentro de um mesmo país, uma contingência recorrente em zonas onde o neo colonialismo se aprofunda. Em seu comemorado livro "O Amor Líquido", traduzido e publicado no Brasil em 2004, Zygmunt Bauman dá um grito de alerta para chamar atenção sobre o espectro que paira sobre o planeta, além dos já previsíveis: o espectro da xenofobia "Suspeitas e animosidades tribais antigas e novas, jamais extintas, recentemente descongeladas misturaram-se e fundiram-se a uma nova preocupação, a da segurança, destilada das incertezas e intranqüilidades da existência líquido -moderna" 19. Quais as razões da intranqüilidade fomentadora da xenofobia: por que a presença do estrangeiro, (o outro) nunca foi tão temida? As populações dos países hospedeiros estão se comportando como se estivessem sendo invadidas por seres extra terrestres e não por seres humanos simplesmente. E nem estão sendo invadidas propriamente, mas 0 processo de colonização inicial está se completando com a expulsão de grandes contingentes populacionais do processo produtivo pós-moderno. E estes buscam abrigo junto àqueles que os expulsaram no passado gozando hoje os louros das vitórias e grandezas acumuladas. Mas não encontram, e antes são violentamente rechaçados como

\footnotetext{
${ }^{19}$ Bauman, Zygmunt (2004). Amor Líquido: sobre a fragilidade dos laços humanos, Rio de Janeiro: Zahar, p. 143.
} 
cidadãos de segunda classe. E nem são cidadãos porque sua cidadania de origem está perdida e não conseguem o mesmo status nos países hospedeiros. São simplesmente humanos sem os seus direitos.

\section{O maior perigo para a humanidade é a abstrata nudez de "não ser nada além de}

humana"

(Edmund Burke)

"Os direitos humanos são uma abstração, e os seres humanos não podem esperar que eles garantam muita proteção, disse ele, a menos que essa abstração seja preenchida com a sua substância em que consistem os direitos dos ingleses ou dos franceses" 20. Que direitos tinham os africanos quando foram deportados para o Brasil no século XVII se eles nem eram considerados seres humanos? nem mesmo o batismo forçado a que foram submetidos e identificados com a marca da cruz na pele conseguiu transformá-los em humanos na perspectiva de uma época que ainda via algo de sagrado no caráter de humanidade do ser, pois no geral como observou Hannah Arendt, o mundo nada descobriu de sagrado na abstrata nudez do ser humano ${ }^{21}$. Em 1789, depois de séculos de um iluminismo construído a duras penas, instituíram-se os direitos do homem e do cidadão, uma frase que ficaria melhor apenas com o segundo protagonista, porque estes direitos resguardados referem-se ao cidadão e não ao homem, pura e simplesmente embora o primeiro esteja contido no segundo. A Constituição brasileira que em 1816 assumiu todos os itens da carta francesa no capítulo dos direitos humanos e do trabalho livre, permitiu no entanto que a escravidão prosseguisse até mais de um século após. Os escravos africanos e seus descendentes continuariam por mais de um século depois, sua marcha lenta em direção a uma liberdade que thes doaria uma condição de cidadãos, mas cidadãos de segunda classe, alocados em espaços desvalorizados, como foram alocados aqui e nos Estados Unidos sobretudo, onde essa condição aparente transfere-se aos instrumentos cotidianos da vida urbana, como os meios de transportes. $\mathrm{E}$ se aqui no Brasil a miscigenação ocultou, em parte, o preconceito, foi necessária a promulgação de uma lei para que este preconceito aflorado em qualquer situação de litígio leve, onde os cidadãos que se vêem como brancos apontam a condição negra do concidadão vizinho, fosse eliminado ou diminuído. Diminuído talvez, eliminado, ainda não.

\footnotetext{
${ }^{20}$ Bauman, Zygmunt (2004). Op. Cit, p.151.

${ }^{21}$ Arendt, Hannah (2001). A Condição Humana, Rio de Janeiro: Forense Universitária, p. 300.
} 
Precisaremos de mais umas duas ou três gerações e muitas providências políticas e educacionais no sentido da homogeneização dos privilégios e dos meios para atingir metas socialmente comparáveis para todos.

\section{Voltando ao erotismo}

Não sei se poderíamos chamar de erotismo ao assédio do colonizador branco europeu às índias e escravas negras do século XVII no Brasil Colônia. Poderíamos sim, se encararmos aqui o erotismo como um dispositivo de poder de um povo que domina o outro e alguém que impõe sua vontade sobre um parceiro mais fraco.

Freyre nunca usou a palavra erotismo para definir as atitudes do colonizador em relação aos povos conquistados e transformados em escravos. Fala em hibridismo, em maleabilidade na interação com outras raças (embora tenha definido seu critério escolhido para análise o conceito cultural) em facilidade na execução da tarefa civilizatória por ser herdeiro de uma sociedade extremamente híbrida, sincrética, quase polifônica etc. Esta tarefa é também propiciada pela escassez de mulheres brancas naquela conjuntura histórica, mais um componente no rol dos elementos que explicam a facilidade da miscigenação. Uma miscigenação, segundo Freyre, democratizante, pois admitiu a ascensão social paulatina do mulato, filhos bastardos entre os filhos legítimos dos senhores de engenho brancos, em plena Casa-Grande, filhos que mais tarde viriam a formar a própria raiz da elite econômica e cultural brasileira.

$\mathrm{Na}$ distante Colônia, ainda não chegavam os ecos que na Europa, Inglaterra principalmente, o vitorianismo impunha sobre os comportamentos, controlando ao máximo as regras da sexualidade e preparando as massas para o cumprimento estrito das tarefas do mundo do trabalho.

O poder da igreja católica reduzia-se diante do poder imenso dos Senhores no controle dos seus domínios, o triângulo rural e sua massa enorme de escravos da qual usava e abusava a seu bel prazer. Nada mais propício ao desenvolvimento do exercício do arbítrio, seja sexual, seja legal, nestas paragens onde a lei era ditada pelo Senhor do Engenho, que fazia filhos com negras e matava escravos, quando lhe apetecia. $E$ o erotismo do colonizador não possui o caráter, visto desse ponto de vista, de um ato de resistência contra regras estabelecidas, porque na verdade não havia regras. Melhor encará-lo então como um ato de violência, uma forma de transgressão ao plano do 
cristianismo, apesar das consequências benéficas que possam daí ter advindo. Sagrado e proibido confundem-se segundo George Bataille e portanto o acesso ao sagrado é através do $\mathrm{Mal}^{22}$. Mas é importante também enfatizar que o erotismo é parte de nossa vida interiorizada e creio que daí, dessa condição vem a força positiva de seu ímpeto. É um ato de resistência na medida em que é interior, instintivo e espontâneo, não se moldando às restrições e proibições. Escapa assim das posturas normativas em que se estabelecem as regras. É, portanto, um elemento social de transgressão e como tal instaurador de mudanças. Mas para promover o diálogo entre povos de diferentes etnias e culturas terá que perder seu caráter de violência. A transgressão sempre estará presente em sua existência porque o caráter sagrado de que é revestido até hoje se revela na sua existência submersa em algumas sociedades. E permanece revestido do caráter instintivo e espontâneo, guardando a violência que lhe é própria. Esta não é uma ideia descartada pela modernidade, mas Foucault nos aponta novos caminhos para 0 conhecimento do problema. Através das práticas sociais ancoradas nos mecanismos de poder que dão origem às problemáticas modernas e atuais. Para Foucault, o erotismo é visto como mais um dos discursos engendrados pelas práticas sociais de uma época que constituem uma rede de formações discursivas que fazem uso das múltiplas relações de poder. É uma tendência que a partir do capitalismo o poder não se interessou em coibir mas ao contrário incentivou, através do incitamento dos discursos. O século XIX tornou-se exemplar dessa fase. A psicanálise freudiana é seu momento mais importante mas além deste, outros discursos médicos e educacionais sobre a sexualidade, disfarçados numa aparente neutralidade, incitam e controlam os desejos e os prazeres. A partir deste momento, o corpo passa a ter importância primordial para a vida social econômica e política, isto é, depois de convenientemente treinado e dotado de uma docilidade que lhe foi imposta através dos séculos. Mas estes discursos não são neutros como seria de esperar. São carregados da subjetividade da fonte produtora e contém alta dose de incitação. Assim, já foi dito de um livro científico como Casa Grande \& Senzala que ele deixa transparecer o caráter altamente erótico de quem o assina. Outra questão esclarecida por Foucault é a de que o erotismo, embora interiorizado individualmente, tem um dispositivo de classe. Conhecemos o ascetismo burguês de que nos falou Max Weber, assim como a nova ética do trabalho instalada a partir da Reforma. Mas também não se trata de uma renúncia ao corpo. Trata-se ao contrário, da maximização da vida através do

\footnotetext{
${ }^{22}$ Bataille, Georges (1980). O erotismo: o proibido e a transgressão, Lisboa: Moraes Editores.
} 
aperfeiçoamento do mesmo. A burguesia e sua descendência são o apanágio desse programa que se estenderia mais tarde às outras classes em função de estratégias econômicas bem definidas. O mais importante é que o caráter instintivo e espontâneo do erotismo permaneça, assim como seu caráter transgressor instaurador de mudanças e capaz de exercer resistência ao poder. As mudanças raciais e culturais instauradas em nossa sociedade são um bom exemplo dessa potencialidade erótica. Uma espontaneidade que promove a união dos corpos não importando a raça ou a cultura que eles portam. No Brasil, a sexualidade e o erotismo foram os grandes elementos propulsores de mudança e da construção de uma ideia de nação nova, vista positivamente por uns e negativamente por outros, mas nova e mais democrática do ponto de vista das práticas interativas das classes sociais e das cores. Uma nação heterocromática e miscigenada. Este foi um processo instaurado ainda na Colônia o que acontece no início através da violência dos Senhores de terras e homens. Ainda assim inaugurou um processo de interação erótica e social que mais tarde viria a trocar o vetor erótico colocado na negra ou mulata libidinosa, para o setor masculino, para o macho considerado superior ao branco na avaliação sexual simbólica feita pela população feminina branca, que aprecia as qualidades do mulato sensual e bem dotado. Este segundo caso propiciará a articulação entre raça e prestígio social pois tendo se tornado o negro um "bem" no mercado de relações sexuais e afetivas, o casamento com uma branca lhe trará prestígio como forma de compensar o estigma da "cor negra" e ingressar em grupos de status e modos de vida similares: "Como visto, a possibilidade de manobrar e compensar o estigma da cor com elementos de prestígio aparece representada - dadas as possibilidades e adjetivações utilizadas pelos autores - mais ao alcance dos homens "negros" e "mulatos", que das mulheres da mesma cor, confinadas, seja positiva, ou negativamente, na chave do erotismo e da beleza. Se neste aspecto aparecem como superiores às brancas (em geral ausentes ou deserotizadas, ou passivas) estes não lhes são entretanto atributos de prestígio, que funcionem na perspectiva dos autores, como senha de acesso ao mercado das alianças formais. Dos autores examinados por Laura Moutinho em Paixão Cor e Desejo, Gilberto Freyre e Peter Fry, dentre outros, a respeito desta questão, os que mais evocam o erotismo, como elemento presente nos pares afetivos sexuais inter raciais são Gilberto Freyre e Roger Bastide. Mas não articulam nas suas narrativas os elementos de prestígio à noção de classe social. Em Gilberto Freyre, um grupo de elementos de prestigio é citado entre eles o erotismo sinalizando para a chance do mulato bacharel eugênico e eutênico, no mundo dos afetos e prazeres, e da 
conjugalidade. Um conhecimento antecipado do que na atualidade viria a se confirmar como conclusão estatística, é o que sugere Laura Moutinho em seu festejado livro. Para nós, apenas mais uma confirmação da capacidade transformadora do erotismo, após ter sido domado pelas práticas sociais inauguradas pelo liberalismo burguês em direção às sociedades mais democráticas, numa perspectiva que engloba os aspectos racial, cultural e econômico, de homens e mulheres em interação social .

\section{Referências}

Araujo, Ricardo Benzanquem (1994). Guerra e Paz: Casa Grande \& Senzala e a Obra de Gilberto Freyre nos anos 30, Rio de Janeiro: Editora 34 Letras.

Arendt, Hannah (2001). A Condição Humana, Rio de Janeiro: Forense Universitária.

Bataille, Georges (1980). O erotismo: o proibido e a transgressão, Lisboa: Moraes Editores.

Bauman, Zygmunt (2004). Amor Líquido: sobre a fragilidade dos laços humanos, Rio de Janeiro: Zahar.

Burke, M. L. G. P (2005). Gilberto Freyre: Um Vitoriano nos Trópicos, São Paulo: EdUnesp.

Costa, Jurandir Freire (1980). Sem fraude nem favor: estudos sobre o amor romântico, Rio de Janeiro: Ed. Rocco.

Costa Lima, L. (1994). "Apresentação". In Araujo, Ricardo Benzanquem (1994). Guerra e Paz: Casa Grande \& Senzala e a Obra de Gilberto Freyre nos anos 30, Rio de Janeiro: Editora 34 Letras.

Foucault, Michel (1984). Historia da sexualidade I: a vontade de saber, Rio de Janeiro: Edições Graal.

. Historia da sexualidade II: O uso dos prazeres, Rio de Janeiro: Edições Graal.

Freyre, Gilberto (1977). Casa Grande y senzala, Introducion a la Historia de la Sociedad Patriarcal en el Brasil, Venezuela: Biblioteca Ayacucho.

Lopes, Nei (2006). Bantos, Malês e Identidade Negra, Belo Horizonte: Autêntica.

Moutinho, Laura (2004). Razão, cor e desejo: uma análise comparativa sobre relacionamentos afetivos-sexuais "inter -raciais" no Brasil e na África do Sul, São Paulo: Ed. UNESP . 
Peixoto, Afrânio (1980). Breviário da Bahia, Rio de Janeiro: MEC - Conselho Federal de Cultura.

Rodrigues, Nina (1977). Os africanos no Brasil, São Paulo: Cia Editora Nacional.

Romero, Sílvio (1953). História da literatura brasileira, Rio de Janeiro: J. Olympio.

Vianna, Oliveira (1959). Raça e assimilação, Rio de Janeiro: J. Olympio.

Recebido para publicação em julho de 2012.

Aprovado para publicação em novembro de 2012. 